\title{
The awareness of anaphylaxis reaction to local anesthesia in Dentistry
}

\author{
Nahid Eskandari ${ }^{1 *}$, Mehrnoush Nekourad ${ }^{2}$ and Reza Bastan ${ }^{3}$ \\ *Correspondence: neskandari@med.mui.ac.ir \\ 'Department of Immunology, Faculty of Medicine, Isfahan University of Medical Sciences, Iran. \\ ${ }^{2}$ Dentistry School, Jundishahpoor University of Medical Sciences, Ahvaz. Iran. \\ ${ }^{3}$ Department of Immunpharmacology, Faculty of Medicine, karaj. Iran.
}

\begin{abstract}
Background: Anaphylaxis is one of the rare clinical events specifically related to anesthesia leading to morbidity and mortality. In this manner, the aim of our study was to determine knowledge of Iranian dentists about symptom, sign and management of anaphylaxis to local anesthesia.

Methods: The study was designed with a questionnaire (16 questions) related to anaphylaxis to local anesthesia in Iran. The dentists working in their private office and clinic of medical dentist randomly selected and asked to complete questionnaire.

Results: $72 \%$ of dentists accepted to take part in the study. Although all attendants knew one or more symptoms and signs of anaphylaxis but none of them marked all options related to anaphylaxis. In relation to, about $72.9 \%$ of dentists knew epinephrine as the first choice in the treatment of anaphylaxis shock, but only $20 \%$ of them had kept emergency equipments and facilities such as drugs in their offices to treat shock. This study showed that less than $10 \%$ of the dentists were aware of the recommended dose of epinephrine to use in adults or children.

Conclusion: Our study concludes that some of dentists are not aware of this emergency vital clinical condition. Therefore, dentists should be developed their knowledge on the subject of the causes and treatment of anaphylaxis shock alternatively with attendance in related courses which holding by academic centers.
\end{abstract}

Keywords: Allergy, anaphylaxis, local anesthetics, dentistry

\section{Introduction}

Based on epidemiology studies, the drug which induced anaphylaxis shock has increased within the recent years $[1,2]$. Systemic anaphylaxis is generally recognized as a severe allergic reaction caused by lgE-mediated activation of mast cells, leading to a massive release of vasoactive mediators that induce acute hypotension and shock. The worst manifestations are cardiovascular collapse, bronchospasm and laryngeal oedema [3,4]. The diagnosis of anaphylaxis is based primarily on clinical criteria and is valid even if the results of laboratory tests, such as serum total tryptase levels [5], are within normal limits. Prevention of anaphylaxis depends primarily on the optimal management of patient-related risk factors, strict avoidance of confirmed relevant allergen or other triggers. Any drug administered can potentially produce life-threatening immune mediated hypersensitivity reactions [6]. Anaphylaxis is the most urgent of clinical allergic reactions. Therefore, if a drug-induced allergic disorder is suspected, consultation with an allergist experienced in the identification, diagnosis and management of drug allergy is recommended.

Anaphylactic reactions to local anaesthetics and associated agents used during dental procedures have been reported with increasing frequency in most developed countries. The incidence of anaphylaxis is, however, very rare and the incidence of anaphylaxis and anaphylactoid reactions during anesthesia is very difficult to estimate but has been calculated to range from 1 in 3,500 to 1 in 13,000 cases [7,8]. Another report from Australia estimated the incidence to be between 1 in 10,000 and 1 in 20,000, whereas the most recent report, from Norway, estimated the incidence to be 1 in 6,000 [9-11]. It is not clear whether dentists are familiar with the symptoms, signs and management of anaphylaxis. Therefore, the aim of our study was to determine knowledge of Iranian dentists about symptom, sign and management of anaphylaxis.

\section{Methods}

The study was performed among dentists working in their private offices and clinics in south area of Iran (Ahwaz and Shiraz) in 2013. The dentists were randomly selected from a list and they were asked if they wanted to join the study. Those who accepted to join the study were visited in their offices or clinics. A questionnaire (Table 1) was prepared which was designed to document the general knowledge of the dentists about the signs, symptoms and management of anaphylaxis. The survey consisted of 16 questions, three of which contained demographic data and 13 questions asking about the LAs and anaphylaxis (Table 1). The questionnaire was distributed to the participating dentists, who were asked to answer the questions without the 
Table 1. The question and answers of dentists.

\begin{tabular}{|c|c|c|}
\hline $\begin{array}{l}\text { The questions } \\
\text { Age (years); }\end{array}$ & \multicolumn{2}{|c|}{ Answers } \\
\hline $25-30$ & 56 & $38.9 \%$ \\
\hline $36-45$ & 57 & $39.6 \%$ \\
\hline$\geq 46$ & 31 & $21.5 \%$ \\
\hline Gender; & 111 & -- \\
\hline Female & 33 & $77.1 \%$ \\
\hline Male & -- & -- \\
\hline \multicolumn{3}{|l|}{ How long have you been working as a dentist (years); } \\
\hline $5 \leq$ & 31 & $21.5 \%$ \\
\hline $6-15$ & 76 & $52.8 \%$ \\
\hline$\geq 16$ & 37 & $25.7 \%$ \\
\hline \multicolumn{3}{|l|}{ You are Qualified as a; } \\
\hline General dents & 105 & $72.9 \%$ \\
\hline Specialist dents & 39 & $27.1 \%$ \\
\hline \multicolumn{3}{|l|}{ Please Write down the names of the local anethesia that you use in your daily practice; } \\
\hline Lidocain & 136 & $94.5 \%$ \\
\hline Articain & 14 & $9.7 \%$ \\
\hline Prilocai & 42 & $29.2 \%$ \\
\hline Others & 6 & $4.2 \%$ \\
\hline \multicolumn{3}{|l|}{ Do you ask your patients if they have any drug allergies before the treatment? } \\
\hline Yes & 133 & $92.4 \%$ \\
\hline No & 11 & $7.6 \%$ \\
\hline \multicolumn{3}{|l|}{ How do you behave when you see a patient with a suspected local anesthesia allergy? } \\
\hline I don't begin the treatment & 4 & $2.8 \%$ \\
\hline I make a skin prick test with the suspected drug by myself & 8 & $5.6 \%$ \\
\hline I refer the patient to an allergy specialist with the suspected the drug for testing & 97 & $67.4 \%$ \\
\hline I treat the patient without Las & 4 & $2.8 \%$ \\
\hline Others & 31 & $21.6 \%$ \\
\hline \multicolumn{3}{|c|}{$\begin{array}{l}\text { How do you behave when you see a patient without any drug allergy, but with any other allergic diseases, such as } \\
\text { asthma or hay fever? }\end{array}$} \\
\hline I make the treatment without considering the other allergic problems & 34 & $23.6 \%$ \\
\hline I accept these problems as a risk factor and refer the patient to the specialist & 110 & $76.4 \%$ \\
\hline \multicolumn{3}{|l|}{ Have you ever seen a patient with systemic adverse reaction due to Las? } \\
\hline Yes & 72 & $50 \%$ \\
\hline No & 72 & $50 \%$ \\
\hline \multicolumn{3}{|c|}{ If you have seen a case with systemic adverse reaction due to local anesthesia, has this occurred during your treatment? } \\
\hline Yes & 70 & $48.6 \%$ \\
\hline No & 74 & $51.4 \%$ \\
\hline \multicolumn{3}{|l|}{ Which symptoms below remind you of anaphylaxis during your treatment? } \\
\hline Nausea and vomiting & 13 & $9 \%$ \\
\hline Shortness of breath & 88 & $61.7 \%$ \\
\hline Skin rash & 35 & $24.3 \%$ \\
\hline Skin swelling & 16 & $11.1 \%$ \\
\hline Hypotension & 50 & $34.7 \%$ \\
\hline
\end{tabular}


Eskandari et al. Journal of Allergy and Asthma 2014,

continuation of Table 1.

\begin{tabular}{|c|c|c|}
\hline The questions & \multicolumn{2}{|c|}{ Answers } \\
\hline Epinephrine & 105 & $72.9 \%$ \\
\hline Antihistamine & 19 & $13.2 \%$ \\
\hline Corticosteroid & 20 & $13.9 \%$ \\
\hline Glucagon & 1 & $0.7 \%$ \\
\hline Salbutamol & 0 & $0 \%$ \\
\hline \multicolumn{3}{|c|}{ Which one of the drugs above do you keep in your office? } \\
\hline Epinephrine & 103 & $71.5 \%$ \\
\hline Antihistamine & 65 & $45.1 \%$ \\
\hline Corticosteroid & 71 & $49.3 \%$ \\
\hline Glucagon & 24 & $16.7 \%$ \\
\hline Sallbutamol & 22 & $15.3 \%$ \\
\hline None of them & 30 & $20.8 \%$ \\
\hline \multicolumn{3}{|c|}{ Which route do you prefer as the initial route for epinephrine injection? } \\
\hline Intramuscular & 33 & $22.9 \%$ \\
\hline Subcutaneous & 64 & $44.4 \%$ \\
\hline Intravenous & 34 & $23.6 \%$ \\
\hline I don’t know & 13 & $0.9 \%$ \\
\hline What is the dose of epinephrine in a $30 \mathrm{~kg}$ child? & 2 & $9.02 \%$ \\
\hline What is the dose of epinephrine in a $70 \mathrm{~kg}$ adult? & 11 & \\
\hline
\end{tabular}

need for an explanation for their conclusions. Results were analysed statistically by using SPSS 10 and Chi-Square test.

\section{Results}

The questionnaire was answered by 144 of 200 (72\%) dentists approached. In This study $77 \%$ of them were male with the mean age being $40 \pm 5$ years and $73 \%$ were general dentists. The mean professional period that was spent in practice was $10 \pm 4$ years.

Prior to the use of any local anaesthesia, most of the dentists (92.4\%) asked the patients about their patients' drug history. According to the results of the questionnaire, every attendant knew one or more symptoms and signs of anaphylaxis but none of them were marked all options related to anaphylaxis. The answers to the questions related to the symptoms and signs of anaphylaxis were similar in all age groups. $61 \%$ of the dentists answered dyspnea as a first symptom in anaphylactic shock. In addition, most of dentists had the necessary knowledge about the importance of emergency medicine at their clinics $-72.9 \%$ knew epinephrine as the first choice in the treatment of anaphylaxis. This was more significant amongst specialist dentists. $20 \%$ of them had kept emergency drugs in their offices to treat shock. Moreover, 33 (22.9\%) of dentists were aware of the fact that epinephrine should be administered using the intramuscular (IM) route when required (Table 1). About $30 \%$ of the dentists considered antihistamines and $45.4 \%$ corticosteroids to be the first-line therapy in anaphylaxis.
$50 \%$ of the dentists had seen patients with a systemic adverse reaction caused by LAs and $48.6 \%$ of them had used antihistamines and corticosteroids for the treatment of the reactions in their own practice. This study showed that less than $10 \%$ of the dentists were aware of the recommended dose of epinephrine to use in adults or children.

\section{Discussion}

Drug allergy is one type of unpredictable adverse drug reaction (ADRs) that encompasses a spectrum of immunologicallymediated hypersensitivity reactions with varying mechanisms and clinical presentations. It accounts for approximately 5-10\% of all ADRs $[12,13]$. Most people who have a genuine allergic reaction to local anesthetics are not allergic to the actual anesthetic agent (or "caine") [14]. It is much more common (though still rare) to be allergic to preservatives in the local anesthetic solution (i.e. IgE mediated). Another possible rare cause of an immediate-type reaction to local anesthesia is preservative related, such as bisulfite that is present in multidose vials. However, atopic diseases, such as heyfever, asthma and allergic rhinitis are not risk factors for local anaesthetic sensitivity, but lots of patients with atopic diseases are referred to allergy clinics by the dentists for assessment for drug allergy.

Dentists can only practice if they graduate from a Dental School. To obtain a placement in a dental school, students have to go through a rigorous education curriculum at the 
Eskandari et al. Journal of Allergy and Asthma 2014,

http://www.hoajonline.com/journals/pdf/2054-9873-1-1.pdf

High School level involving a very difficult and competitive examination. Moreover, education programmes in Iranian dentistry schools are the same as those in most developed country. Therefore, the candidates practicing dentistry are highly trained and extremely capable.

Anaphylaxis is one of the most urgent clinical pictures in daily medical practice. Manifestations from the skin to the cardiovascular and respiratory systems are present simultaneously in approximately $70 \%$ of patients. Anaphylaxis should be diagnosed and treated immediately [15]. Since anaphylaxis may also be encountered by dentists, although not common-in their routine practice, they should also be aware of the symptoms and signs of anaphylaxis, and treat the severe reactions in the light of recent advances [16]. The most effective strategy for the management of drug allergy is avoidance or discontinuation of the offending drug. When available, alternative medications with unrelated chemical structures should be substituted. Cross-reactivity amongst drugs should be taken into consideration when choosing alternative agents. In the event of an anaphylaxis episode, the treatment of choice is epinephrine administered by intramuscular injection into the lateral thigh [17]. Contrary to other study [18], our study show that most of the dentists who practise in their private offices are aware of this fact.

Epinephrine, antihistamines and corticosteroids are not expensive and so should be kept in all medical centres[19]. In contrast to other research [18] , our study show that about $71 \%$ of the dentists keep epinephrine ready in their offices. The recommended practise of administration of epinephrine using the IM route was similar to the others studies. However, some dentists did not know the importance of this. About $23 \%$ of dentists preferred IV route for epinephrine. This can cause a very dramatic increase in the heart rate leading to serious consequences. The recommended dose of epinephrine is based on the patients' body weight. The usual dose for children and adults who weigh $30 \mathrm{~kg}$ or over is $0.3 \mathrm{mg}$. For adults and children who weigh $15 \mathrm{~kg}$ to $30 \mathrm{~kg}$, the dose is $0.15 \mathrm{mg}[20,21]$. In this order, the study shows that most of the dentists were not aware of the recommended dose of epinephrine to use in adults or children.

Systemic corticosteroids and antihistamine may also be used to treat severe systemic reactions $[22,23]$, but should never be given prior to or as a substitute for epinephrine in the treatment of anaphylaxis. In this study as is the case with other studies [18], some of the dentists use corticosteroids or antihistamine as the first choice of drug in the management of anaphylaxis.

In conclusion, allergic reactions during the administration of local anaesthesia are rare but if it occurs, can be potentially life-threatening. Most dentists who encounter patients with anaphylaxis in their clinics or private offices do not seem to be aware of this urgent condition. This trend has increased in this field in the last few years. Hence, dentists should be more aware of the causes and treatment of anaphalaxis. In addition it could be completed by nationwide educational programs on anaphalaxis such as congresses, seminars, workshops and journal clubs for dentists.

\section{Competing interests}

The authors declare that they have no competing interests.

Authors' contributions

\begin{tabular}{|l|c|c|c|}
\hline Authors' contributions & NE & MN & RB \\
\hline Research concept and design & $\checkmark$ & -- & $\checkmark$ \\
\hline Collection and/or assembly of data & -- & $\checkmark$ & -- \\
\hline Data analysis and interpretation & $\checkmark$ & $\checkmark$ & -- \\
\hline Writing the article & $\checkmark$ & -- & $\checkmark$ \\
\hline Critical revision of the article & $\checkmark$ & -- & -- \\
\hline Final approval of article & $\checkmark$ & -- & -- \\
\hline Statistical analysis & $\checkmark$ & $\checkmark$ & -- \\
\hline
\end{tabular}

Acknowledgement

The authors wish to thanks all dentists which contributed to this project.

\section{Publication history}

Editor: Donald Cockcroft, University of Saskatchewan, Canada. Received: 17-Dec-2013 Revised: 30-Dec-2013

Accepted: 11-Jan-2014 Published: 28-Jan-2014

\section{References}

1. Worm M. [Epidemiology of anaphylaxis]. Hautarzt. 2013; 64:88-92. | Aritcle | PubMed

2. Worm $M$, Babina $M$ and Hompes $S$. Causes and risk factors for anaphylaxis. J Dtsch Dermatol Ges. 2013; 11:44-50. | Aritcle I PubMed

3. Przybilla B, Ring J and Rueff F. [Anaphylaxis. Clinical manifestations and diagnosis]. Hautarzt. 2007; 58:1025-31. | Aritcle I PubMed

4. Bartolomei FJ and McCarthy DJ. Anaphylaxis: mechanisms, manifestations, and management. J Foot Surg. 1984; 23:485-8. | Aritcle | PubMed

5. Michalska-Krzanowska G. Tryptase in diagnosing adverse suspected anaphylactic reaction. Adv Clin Exp Med. 2012; 21:403-8. | Pdf | PubMed

6. Chiu CY, Lin TY, Hsia SH, Lai SH and Wong KS. Systemic anaphylaxis following local lidocaine administration during a dental procedure. Pediatr Emerg Care. 2004; 20:178-80. | Aritcle | PubMed

7. Vervloet D, Magnan A, Birnbaum J and Pradal M. Allergic emergencies seen in surgical suites. Clin Rev Allergy Immunol. 1999; 17:459-67. | Aritcle | PubMed

8. Laxenaire MC. [Again and always allergy]. Ann Fr Anesth Reanim. 1999; 18:831-3. I Aritcle I PubMed

9. Hepner DL and Castells MC. Anaphylaxis during the perioperative period. Anesth Analg. 2003; 97:1381-95. I Aritcle I PubMed

10. Lieberman P, Camargo CA, Jr., Bohlke K, Jick H, Miller RL, Sheikh A and Simons FE. Epidemiology of anaphylaxis: findings of the American College of Allergy, Asthma and Immunology Epidemiology of Anaphylaxis Working Group. Ann Allergy Asthma Immunol. 2006; 97:596-602. | Aritcle | PubMed

11. Webb LM and Lieberman P. Anaphylaxis: a review of 601 cases. Ann Allergy Asthma Immunol. 2006; 97:39-43. | Aritcle I PubMed

12. Dewachter $P$, Mouton-Faivre $C$ and Emala CW. Anaphylaxis and anesthesia: controversies and new insights. Anesthesiology. 2009; 111:1141-50. | Aritcle | PubMed

13. Sicherer SH and Leung DY. Advances in allergic skin disease, anaphylaxis, 
Eskandari et al. Journal of Allergy and Asthma 2014,

http://www.hoajonline.com/journals/pdf/2054-9873-1-1.pdf

and hypersensitivity reactions to foods, drugs, and insects in 2012. J Allergy Clin Immunol. 2013; 131:55-66. | Aritcle I PubMed

14. Pavlidakey PG, Brodell EE and Helms SE. Diphenhydramine as an alternative local anesthetic agent. J Clin Aesthet Dermatol. 2009; 2:3740. | PubMed Abstract | PubMed Full Text

15. Lieberman P. Anaphylaxis. Med Clin North Am. 2006; 90:77-95. | Aritcle I PubMed

16. Sampson HA, Munoz-Furlong A, Campbell RL, Adkinson NF, Jr., Bock SA, Branum A, Brown SG, Camargo CA, Jr., Cydulka R and Galli SJ et al. Second symposium on the definition and management of anaphylaxis: summary report--second National Institute of Allergy and Infectious Disease/Food Allergy and Anaphylaxis Network symposium. Ann Emerg Med. 2006; 47:373-80. | Aritcle | PubMed

17. Simons $\mathrm{KJ}$ and Simons FE. Epinephrine and its use in anaphylaxis: current issues. Curr Opin Allergy Clin Immunol. 2010; 10:354-61. | Aritcle I PubMed

18. Cetinkaya F, Sezgin $G$ and Aslan OM. Dentists' knowledge about anaphylaxis caused by local anaesthetics. Allergol Immunopathol (Madr). 2011; 39:228-31. | Aritcle | PubMed

19. Anchor J and Settipane RA. Appropriate use of epinephrine in anaphylaxis. Am J Emerg Med. 2004; 22:488-90. | Aritcle | PubMed

20. Simons FE. Pharmacologic treatment of anaphylaxis: can the evidence base be strengthened? Curr Opin Allergy Clin Immunol. 2010; 10:384-93. | Aritcle | PubMed

21. Lee JK and Vadas P. Anaphylaxis: mechanisms and management. Clin Exp Allergy. 2011; 41:923-38. | Aritcle | PubMed

22. Sheikh A. Glucocorticosteroids for the treatment and prevention of anaphylaxis. Curr Opin Allergy Clin Immunol. 2013; 13:263-7. | Aritcle | PubMed

23. Sheikh A, ten Broek V, Brown SG and Simons FE. H1-antihistamines for the treatment of anaphylaxis with and without shock. Cochrane

Citation:
Eskandari N, Nekourad M and Bastan R. The
awareness of anaphylaxis reaction to local
anesthesia in Dentistry. J Allergy Asthma.
2014; $1: 1$.
http://dx.doi.org/10.7243/2054-9873-1-1

